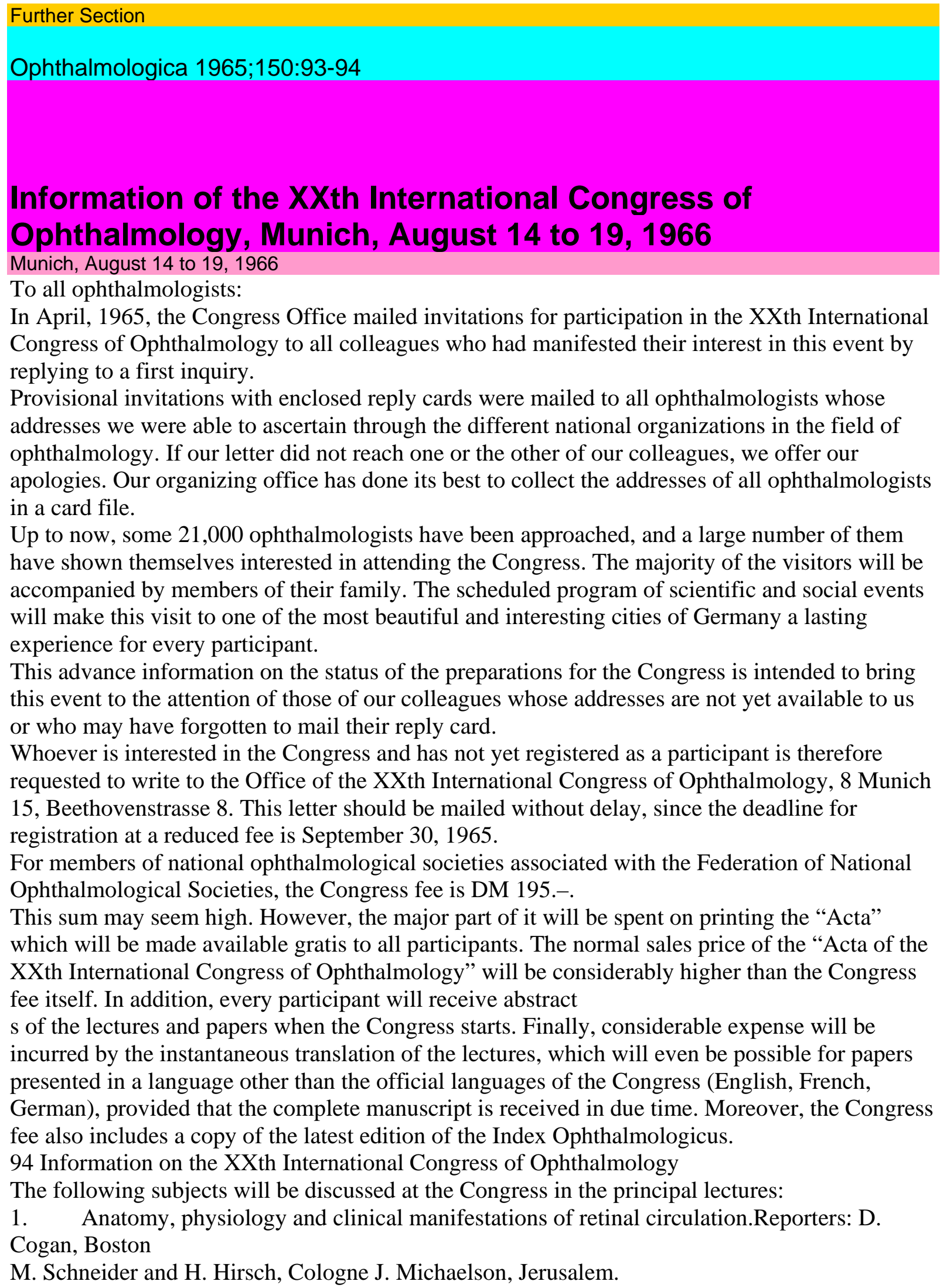




\section{Uveitis in childhood.}

Reporters: F. Palomeno Dena, Mexico E. S. Perkins, London R. W. Witmer, Zurich.

Round-table talks will deal with the infection of the anterior portion of the globe by viruses and fungi (moderator: G. Bietti, Rome), and with the evaluation of the results of the therapeutic treatment by statistical methods (moderator: A. Linder, Geneva).

During the congress, there will be reports and discussions on the results of 5 symposia to be held at different places a few days before the Congress. These are:

the symposion of the Jules Gonin Club (President: G. Meyer-Schwickerath, Essen)

the symposion on the biochemistry of the eye (President: J. Nordmann, Strasbourg)

the symposion on electroretinography (President: J. Francois, Gent)

the symposion on glaucoma (President: H. Goldmann, Berne)

the symposion on strabism (President: A. Jampolsky, San Francisco).

The program of lectures will be completed by free communications and discussions on the principal subjects.

The latest and best films on ophthalmological subjects will be shown. In addition, there will be an exhibition of scientific material which we trust will be highly interesting. Commercial organizations connected with the field of ophthalmology have also been asked to exhibit their latest products.

After the period of the Congress, a choice of several organized tours through Germany and Europe is offered, for which a travel agency has prepared detailed suggestions.

Good and particularly modestly priced accommodation is available for young ophthalmologists who have not yet completed their studies.

The organizers of the Congress would be highly pleased if a large part of the world family of ophthalmologists would follow the invitation to attend the XXth International Congress of Ophthalmology. Each and every colleague will be a most welcome guest.

H. K. Mailer, Bonn

P. President of the XXth International

Congress of Ophthalmology. 